\title{
ENERGIA FOTOVOLTAICA RESIDENCIAL: UMA ANÁLISE ECONÔMICO FINANCEIRA DE VIABILIDADE
}

\author{
Valdir Serafim Junior ${ }^{1}$ \\ Álvaro Henrique Sbaraini² \\ Cristiano Goulart ${ }^{3}$ \\ Juliane Vanderlinde Hort ${ }^{4}$ \\ Armin Feiden ${ }^{5}$
}

SERAFIM JUNIOR, V.; SBARAINI, A. H.; GOULART, C.; HORT, J. V.; FEIDEN, A. Energia fotovoltaica residencial: uma análise econômico financeira de viabilidade. Rev. Ciênc. Empres. UNIPAR, Umuarama, v. 19, n. 2, p. 273290, jul./dez. 2018.

RESUMO: O presente estudo analisou a viabilidade econômico-financeira da instalação de um sistema de energia solar fotovoltaica, com cálculos de análise financeiros como VPL, TIR, tempo de retorno de investimento (payback), objetivando a possibilidade de redução de custos de uma residência na região da Costa Oeste do Paraná com a análise de perfil de possíveis usuários. Caracterizou-se como uma pesquisa aplicada de tipologia exploratória, bibliográfica e descritiva, gerando análises qualitativas e quantitativas, utilizando-se de métodos de análise financeira, gerando resultados para a tomada de decisão. Os resultados encontrados revelam que os entrevistados tem perfil de pequenos consumidores e estariam dispostos a investir em um sistema de energia fotovoltaica, quanto a viabilidade do investimento, foi identificado através da análise do payback descontado, que o mesmo terá retorno em $34,92 \%$ do tempo de sua vida útil estima-

DOI: $10.25110 /$ receu.v19i2.6868

${ }^{1}$ Bacharel em Ciências Contábeis, Pós-Graduado em Gestão de Negócios e Auditora, Mestre em Desenvolvimento Rural Sustentável, Doutorando no PPGDRS - Programa de Pós-Graduação em Desenvolvimento Rural Sustentável pela UNIOESTE - Universidade Estadual do Oeste do Paraná Campus de Marechal Cândido Rondon.

${ }^{2}$ Engenheiro Agrônomo, Mestrando no PPGDRS - Programa de Pós-Graduação em Desenvolvimento Rural Sustentável pela UNIOESTE - Universidade Estadual do Oeste do Paraná - Campus de Marechal Cândido Rondon.

${ }^{3}$ Engenheiro Civil, Mestre em Ciências Ambientais, Doutorando no PPGDRS - Programa de PósGraduação em Desenvolvimento Rural Sustentável pela UNIOESTE - Universidade Estadual do Oeste do Paraná - Campus de Marechal Cândido Rondon.

${ }^{4}$ Bacharel em Ciências Biológicas, Mestre em Desenvolvimento Rural Sustentável, Doutoranda no PPGDRS - Programa de Pós-Graduação em Desenvolvimento Rural Sustentável pela UNIOESTE Universidade Estadual do Oeste do Paraná - Campus de Marechal Cândido Rondon.

${ }^{5}$ Zootecnista, Agrônomo, Mestre em Engenharia Florestal, Doutor em Agronomia, Professor associado da UNIOESTE, Universidade Estadual do Oeste do Paraná no PPGDRS - Programa de Pós-Graduação em Desenvolvimento Rural Sustentável - Campus de Marechal Cândido Rondon. 
da, correspondente a 8,73 anos apresentando uma TIR - Taxa Interna de Retorno de $8 \%$, superior à taxa mínima de atratividade utilizada de 6,99\% a.a., correspondente ao rendimento acumulado da poupança no ano de 2017, além também de benefícios ambientais pelo uso de fonte de energia renovável.

PALAVRAS CHAVE: Energia renovável; Investimento; Atratividade.

\title{
RESIDENTIAL PHOTOVOLTAIC ENERGY: A FINANCIAL AND ECONOMIC VIABILITY ANALYSIS
}

\begin{abstract}
This study analyzed the economic and financial feasibility of installing a photovoltaic solar energy system, with the financial analysis calculations such as NPV, IRR and payback time, among others, aiming at the possibility of reducing the costs of a residence in the region of the West Coast of Paraná, in addition to the profile analysis of possible users. It was characterized as an applied exploratory, bibliographic and descriptive research, generating qualitative and quantitative analyzes, using financial analysis methods, providing insights for the decision-making process. The results show that the respondents have the profile of small consumers and would be willing to invest in a photovoltaic energy system. Regarding the feasibility of the investment, through a discounted payback analysis, it was observed that there will be a return of $34.92 \%$ of its estimated useful life corresponding to 8.73 years, presenting an IRR - Internal Rate of Return of $8 \%$, higher than the minimum rate of attractiveness used at $6.99 \%$ p.a., which corresponded to the accumulated income from the savings account in 2017, as well as the environmental benefits from the use of renewable energy sources.
\end{abstract}

KEY WORDS: Renewable energy; investment; attractiveness.

\section{ENERGÍA FOTOVOLTAICA RESIDENCIAL: UN ANÁLISIS ECONOMICO FINANCIERO DE VIABILIDAD}

RESUMEN: El presente estudio analizó la viabilidad económico-financiera de la instalación de un sistema de energía solar fotovoltaica, con cálculos de análisis financieros como VPL, TIR, tiempo de retorno de inversión, con el objetivo de reducir los costos de una residencia en la región de la Costa Oeste de Paraná con el análisis de perfil de posibles usuarios. Se caracterizó como una investigación aplicada de tipología exploratoria, bibliográfica y descriptiva, generando análisis cualitativos y cuantitativos, utilizando métodos de análisis financiero, generando resultados para la toma de decisión. Los resultados encontrados revelan que los entrevistados tienen perfil de pequeños consumidores y estar dispuestos a invertir en un sistema de energía fotovoltaica, en cuanto a la viabilidad de la inversión, 
fue identificado a través del análisis del payback descontado, que el mismo tendrá retorno en el 34,92\% el tiempo de su vida útil estimada, correspondiente a 8,73 años presentando una TIR - Tasa Interna de Retorno del 8\%, superior a la tasa mínima de atractivo utilizada del 6,99\% aa, correspondiente al rendimiento acumulado del ahorro en el año 2017, además de beneficios ambientales por el uso de fuente de energía renovable.

PALABRAS CLAVE: Energía renovable; La inversión; El atractivo.

\section{INTRODUÇÃO}

A geração de energia por meio da utilização de recursos fósseis é reconhecidamente danosa ao meio ambiente. A alta emissão de gases para a atmosfera tem como grande consequência o aquecimento global (SHAYANI et al., 2006). A forma de produção de energia que substituirá o combustível fóssil, precisa ter a preocupação com a sustentabilidade e, obviamente, diminuir a atual degradação do meio ambiente.

As alternativas de energias renováveis estão se expandindo no mundo inteiro e em novos mercados. Segundo dados da Renewable Energy Policy Network (REN), entre 2010 e 2011, o mercado mundial de energias renováveis retomou, após o recuo global em 2009 , com crescimento variando até $74 \%$, que por sua vez, dados bem acima da média histórica do setor. Neste contexto, observou-se que a ênfase foi para mercado de energia solar, com $74 \%$, contudo, houve crescimento também, na eólica com aumento de $20 \%$ e no biodiesel, com aumentos de $16 \%$ (REN, 2013).

Verificando o potencial brasileiro quanto à geração de energia solar por sistemas fotovoltaicos, considerando suas características sustentáveis e de preservação do meio ambiente, é amplamente relevante a análise de investimento para sua instalação, considerando suas vantagens ou desvantagens econômico-financeira. Segundo Camargos (2013), é preciso em uma análise de investimento, a determinação dos rendimentos que se espera pela implantação do projeto, determinando sua viabilidade econômico-financeira.

Dessa maneira, sabendo que que a energia fotovoltaica apresenta potencial de aproveitamento, exploração e produção, o presente estudo teve por objetivo analisar a viabilidade econômico-financeira da instalação de um sistema de energia solar fotovoltaica, com cálculos de análise financeiros como VPL, TIR, tempo de retorno de investimento, objetivando a possibilidade de redução de custos de uma residência na região da Costa Oeste do Paraná, verificando-se a capacidade de geração da região estudada e perfil de possíveis usuários, a análise de custo do investimento do sistema fotovoltaico e seu retorno econômico financeiro do investimento proposto. 
O estudo apresentou-se relevante, primeiramente pelo interesse voltado à alternativa de geração de energia limpa e sustentável, seguido pela possibilidade de análises de redução de custos aos usuários abastecidos pelas companhias de distribuição de energia elétrica.

\section{REVISÃO BIBLIOGRÁFICA}

Na revisão bibliográfica serão apresentados temas que embasam conceitualmente a presente pesquisa, relacionadas à sustentabilidade, energias renováveis e energia fotovoltaica, seguidos dos indicadores para a análise de viabilidade econômico financeira do projeto.

\subsection{Sustentabilidade}

Os conceitos de sustentabilidade são amplamente discutidos, porém a sua empregabilidade é bem baixa, sendo utilizado como pretexto para marketing do que para a execução de ações concretas por meio de cumprimento de metas. A sustentabilidade está atrelada aos componentes sociais, ambientais, econômicos e culturais, gerando um panorama voltado para a qualidade de vida das atuais e das futuras gerações de todas as espécies que hoje existem no planeta, havendo a necessidade de que a humanidade controle suas ambições e aceite os limites ambientais para a preservação da qualidade de vida de outras espécies (DAL SOGLIO; KUBO, 2009).

Para Almeida (2007), concentra-se o bônus, a riqueza em parte auferida pelo uso não sustentável dos serviços ambientais, nas mãos da minoria e distribui-se o ônus, na forma de poluição e quebra da infraestrutura ambiental, para a maioria ou, pior, para as futuras gerações.

A sustentabilidade, em suas mais diversas amplitudes, está intimamente unida à essa premissa, tanto sob um ponto de vista de recursos naturais como também o ponto de vista financeiro, no contexto de não consumir mais recursos do que a respectiva natureza é capaz de renovar (DUPONT et al., 2015).

Para Barbieri (2007) a sustentabilidade apoia-se na ideia de que a exploração preserve a base inicial dos recursos, tendo assim, respeito pelo ambiente e as gerações futuras. Sob esta perspectiva, a utilização de fontes de energia renováveis requer atenção especial.

A ciência moderna deve ser utilizada para a criação de projetos sustentáveis e estes são dependentes da habilidade humana para o seu sucesso, porém são vários desafios para conservação e aproveitamento racional da natureza, devendo-se escolher métodos corretos, planejamentos de sustentabilidade múltiplas da terra, de seus recursos renováveis e planos de sua ocupação, preservando a biodiversidade e o meio ambiente nos seu uso produtivo, assim deve-se com- 
preender que as atividades econômicas estão ligadas ao ambiente natural e que a ciência moderna deve ser utilizada para a criação de projetos sustentáveis e estes são dependentes da habilidade humana para o seu sucesso (SACHS, 2009).

A pesquisa e o desenvolvimento científico, contudo, também devem progredir em busca do desenvolvimento sustentável. A utilização de recursos renováveis não-poluentes, em lugar de, recursos fósseis poluentes, justificados por uma maior eficiência ou possível redução de custos, orientando os esforços para as alternativas e soluções que possam atender às necessidades da humanidade e da natureza (SHAYANI et al., 2006).

\subsection{Energias renováveis}

O desenvolvimento social e econômico tende sempre a buscar demanda por mais energia, por exemplo, enquanto em países desenvolvidos o consumo de eletricidade pode chegar até $10 \mathrm{mil} \mathrm{kWh}$ por pessoa, nos países em que estão em desenvolvimento, nos qual pertence a maior parte da população mundial, esse consumo decai para menos do que 2 mil $\mathrm{kWh}$ por pessoa (PALLIS; CRUZ, 2010).

Diante da poluição atmosférica, chuva ácida e aquecimento global, produzido principalmente pelo $\mathrm{CO} 2$, devido à queima de combustível fóssil. Sendo imprescindível a busca pela sustentabilidade, por meio da adoção de energias renováveis que respondem bem a estas demandas: a maioria corresponde a energias renováveis (energia eólica, eletricidade solar com células fotovoltaicas, solar térmica, e energia de biomassa) tem origem na radiação solar, que por sua vez não é poluente e não vai se esgotar. Além disso, a radiação solar está presente sobre o planeta de uma forma mais justa e com mais acesso a todos do que as fontes fósseis de energia (GOLDEMBERG, 2015).

As alternativas de energias renováveis estão se expandindo no mundo inteiro e em novos mercados. Segundo dados da Renewable Energy Policy Network (REN), entre 2010 e 2011, o mercado mundial de energias renováveis retomou, após o recuo global em 2009, com crescimento variando até $74 \%$, que por sua vez, dados bem acima da média histórica do setor. Neste contexto observou-se que a ênfase foi para mercado de energia solar, com $74 \%$, contudo, houve crescimento também, na eólica com aumento de $20 \%$ e no biodiesel, com aumentos de $16 \%$ (REN, 2013).

\subsection{Energia fotovoltaica}

Historicamente o homem molda a energia solar, por meio dela são supridas as necessidades básicas de iluminação, aquecimento, alimentação e desenvolvimento econômico, porém a sua utilização como fonte direta de produção de eletricidade faz partes de estudos mais recentes, sendo uma das tipologias de 
tecnologia de geração, a fotovoltaica, que consiste na geração direta da luz em eletricidade (REN, 2015).

Segundo Shayani et al. (2006), o procedimento de geração de energia solar fotovoltaica é mais simples do que os outros meios de obtenção de eletricidade, trazendo o seu uso benefícios na diminuição de custos com os sistemas de transmissão e distribuição, contribuindo para a sustentabilidade e desenvolvimento socioeconômico em localidades não eletrificadas.

Outra alternativa vem sendo a energia solar fotovoltaica, que por sua vez, é definida como a energia produzida por meio da conversão direta da radiação solar em eletricidade. Isto é possível, por meio de um dispositivo reconhecido como célula fotovoltaica que atua utilizando o princípio do efeito fotoelétrico ou fotovoltaico (IMHOFF, 2007). Esse contexto de energia solar renovável representa o modelo cordial de sustentabilidade de aproveitamento de recursos ambiental inesgotável.

As fontes renováveis como a fotovoltaica ou eólica apresentam outras particularidades que devem ser atenciosamente estudadas, principalmente no que indica a sua variabilidade na questão tempo. Por um lado, destaca-se uma série de benefícios ambientais, por outro lado um aumento na sensibilidade a questões climáticas como dias sem vento, nublados ou a noite, como consequência uma diminuição na produção de energia (NASCIMENTO, 2017).

Uma possível solução para armazenar a energia gerada pelo sistema fotovoltaico seria o uso de baterias, entretanto, montar um banco de baterias é caro e também possuem vida útil pequena, cerca de 3 a 5 anos. Desse modo, esbarrarão-se em outro empecilho, onde o uso de baterias vai contra a ideia de sustentabilidade, pois possuem elementos extremamente tóxicos, como cádmio e chumbo. Uma sugestão, seria o uso de baterias apropriadas para sistemas fotovoltaicos, que são as de chumbo-ácido (MACHADO; MIRANDA, 2014)

Segundo a Absolar (2018), em janeiro de 2018, o setor ultrapassou a marca histórica de 1 gigawatt (GW) operacionais no Brasil, posicionando o País dentro do prestigiado clube das 30 principais nações do mundo em energia solar fotovoltaica, sendo que até o final do ano, o Brasil ultrapassará a marca de $2 \mathrm{GW}$.

Já são mais de 27 mil sistemas de geração distribuída solar fotovoltaica em telhados, fachadas e coberturas de residências, comércios, indústrias, edifícios públicos e propriedades rurais, somando mais de 246 megawatts (MW) de potência e mais de R \$ 1,6 bilhão em investimentos privados injetados na economia nacional. Entre os fatores que impulsionam o crescimento da microgeração e minigeração distribuída solar fotovoltaica pode-se citar a redução de mais de $75 \%$ no preço da energia solar fotovoltaica na última década e o aumento nas tarifas de energia elétrica. Hoje, sendo que o retorno do investimento em um sistema solar fotovoltaico está entre 5 e 7 anos (ABSOLAR, 2018). 


\subsection{Análise de investimento de capital}

Quando se pensa no investimento em um projeto, existe a necessidade de verificar a sua viabilidade econômica financeira, o presente estudo tem como objetivo viabilidade econômico-financeira da instalação de um sistema de energia solar fotovoltaica, com cálculos de análise financeiros do tempo de retorno de investimento por meio do payback, VPL - Valor Presente Líquido e TIR - Taxa Interna de Retorno, objetivando a possibilidade de redução de custos.

Para Garrison et al. (2012), os investimentos de capital geram retornos em períodos razoavelmente longos, necessitando o conhecimento do valor do dinheiro no tempo para que se possa avaliar as propostas de investimento, preferindo-se as alternativas de retornos mais rápidas, devendo-se efetuar uma análise nos fluxos de caixas previstos para os períodos futuros.

Em uma análise de investimento, se faz necessário a determinação de maneira racional e precisa de uma taxa que o investidor ou a empresa deseja obter de rendimento na implantação do projeto. Essa taxa descapitalizará os fluxos de caixa do projeto de investimento, determinando a sua viabilidade econômico-financeira, é denominada taxa de desconto, custo de capital ou taxa mínima de atratividade (TMA), podendo ser baseada no custo de oportunidade de aplicações existentes no mercado ou baseado no custo de capital da empresa, pela análise médias de suas fontes de recursos (CAMARGOS, 2013).

Para se saber o período de recuperação do investimento inicial, utilizase o método do payback, o qual informa os números de anos necessários para que os fluxos de caixas futuros se igualem ao valor do investimento inicial, representado por dois métodos: payback simples e payback descontado.

Segundo Assaf Neto e Lima (2009), o payback simples não considera o valor do dinheiro no tempo, já o payback descontado o leva em consideração, devido a isso deve ser considerado como o indicador mais adequado, pois ao se ignorar o efeito do dinheiro no tempo, poderá estar se associando um menor risco ao projeto de investimento.

Para Camargos (2013) o VPL é obtido pela diferença entre o valor presente das entradas de caixa previstas para cada período de duração do projeto, e o valor presente do investimento inicial ou das saídas de caixa (quando houver mais de uma). Compara-se o investimento inicial ou as saídas de caixa com os valores futuros dos fluxos de caixas trazidos a valor presente (no tempo zero do investimento), indica o potencial de geração de valor de um investimento.

Em relação a TIR - taxa interna de retorno, representa a rentabilidade que o projeto de investimento oferece para o capital que nele permanece investido, matematicamente é uma taxa efetiva por período, devendo ser comparada à TMA da empresa para tomar a decisão de aceitar ou não o projeto (CAMARGOS, 2013). 


\section{METODOLOGIA}

O presente estudo caracterizou-se por uma pesquisa aplicada de tipologia exploratória, pois seu objetivo é de proporcionar uma visão geral acerca de da viabilidade de investimento na instalação de um sistema de geração de energia fotovoltaica com o propósito de redução de custos, utilizando-se de métodos de análise financeira, gerando resultados para a tomada de decisão.

Para Gil (2008), a pesquisa exploratória proporciona maior familiaridade com o problema, tornando-o mais explícito. Na maioria dos casos assume a forma de pesquisa bibliográfica ou de estudo de caso. O estudo de caso consiste no estudo aprofundado de um ou de poucos objetivos, com o intuito de possibilitar conhecimentos amplos e detalhados.

O presente trabalho caracterizou-se pela tipologia bibliográfica e descritiva uma vez que teve como característica descrever os fatos e fenômenos da realidade, observar, registrar e analisar sem interferência, proporcionando uma nova visão de uma realidade já conhecida.

Segundo Gil (2008), a necessidade de descrição das características e fenômenos, identificados nas variáveis selecionadas, assim como as características dos grupos observados define uma pesquisa como descritiva.

E bibliográfica, pois se baseou em publicações científicas já elaboradas referentes ao assunto da pesquisa, consulta na internet sobre as legislações pertinentes e estatísticas nos principais órgãos governamentais sobre o tema proposto.

Os dados primários foram extraídos de questionários semiestruturados, aplicados de forma eletrônica a indivíduos da região estudada, de orçamentos de empresas fornecedoras e instaladoras de sistemas fotovoltaicos, de instituições de crédito para análise do custo de capital e da concessionária de energia estadual para análise da política de preços; já livros, artigos, leis serviram para os levantamentos bibliográficos.

\section{RESULTADOS E DISCUSSÃO}

Primeiramente, para o embasamento da pesquisa, buscou-se verificar qual o potencial energético fotovoltaico da região foco do estudo de viabilidade de instalação do projeto, a Figura 1 demonstra que o Estado do Paraná possui condições favoráveis para o aproveitamento da energia solar, segundo a UTFPR (2018) em seu Atlas de Energia Solar do Estado do Paraná, o estado apresenta irradiação total média de $1986 \mathrm{kWh} / \mathrm{m} 2$ ano e produtividade total anual média de $1.490 \mathrm{kWh} / \mathrm{kWp}$ ano, sendo compatível com a região da Costa Oeste Paranaense, objeto do estudo. 
Figura 1: Mapa Fotovoltaico do Estado do Paraná - Total Anual

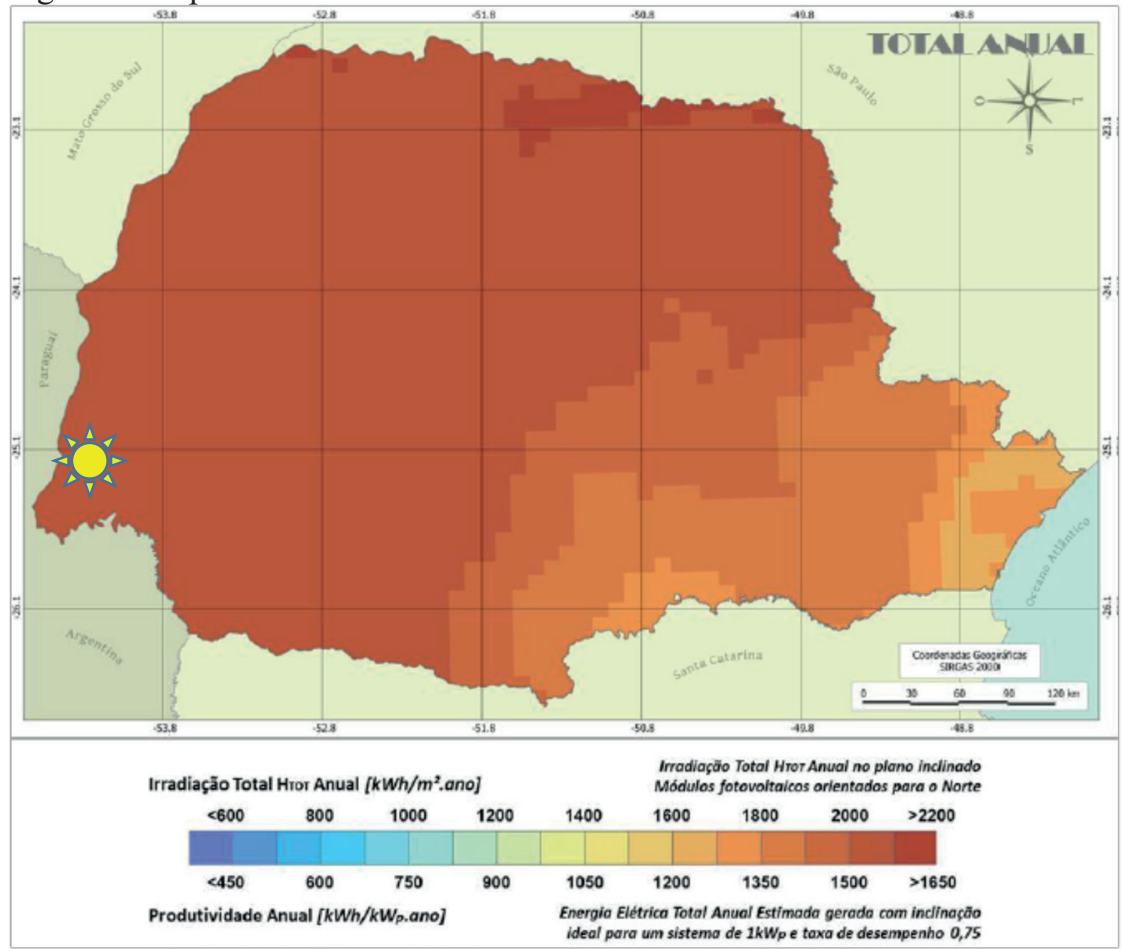

Fonte: UTFPR - Atlas de Energia Solar do Estado do Paraná

Na sequência, foram analisados dos dados retirados dos questionários aplicados via formulário eletrônico, verificando-se por meio da Tabela 1, que 93\% dos entrevistados não possui sistema fotovoltaico residencial instalado; $69 \%$ apresentam nível de conhecimento sobre a geração de energia fotovoltaica de fraco a moderado; sendo que $19 \%$ consideram possuir conhecimento satisfatório; e $12 \%$ informaram possuir nível muito bom e excelente.

O reflexo do baixo nível de conhecimento sobre o assunto abordado, corrobora para índices encontrados relacionados com a importância que os entrevistados dispensam ao tema, em que 65\% declararam estar em níveis fracos e moderados; $17 \%$ nível satisfatório; e 19\% nível muito bom e excelente.

Quanto às medidas de redução de consumo e uso consciente de energia elétrica adotadas pelos entrevistados: $43 \%$ consideram que são fracas a moderadas; $29 \%$ consideram que são satisfatórias e; $29 \%$ em níveis muito bons a excelestes. Mesmo com índices maiores no agrupamento satisfatório, muito bom e 
excelente, chama a atenção o montante expressivo de entrevistados que afirmaram considerarem suas medidas adotadas como fracas ou moderadas.

Quanto à outras fontes de energias: $81 \%$ consideram importantes em níveis satisfatório, muito bom e excelente, sendo que $57 \%$ dos entrevistados foram convictos em responder que estariam dispostos a pagar mais por energias de fontes sustentáveis.

Os entrevistados apresentaram perfil de pequenos consumidores, concentrados em faixas de consumo superiores a $150 \mathrm{kWh}$ mensais, que estariam dispostos a investir em um sistema de energia fotovoltaica, mesmo com parcela de investimento acima do valor pago na atualidade em relação ao consumo de energia elétrica. Consideram que o custo do sistema e a falta de políticas de incentivo são as maiores dificuldades para o investimento.

Tabela 1: Percepção dos entrevistados sobre geração de energia fotovoltaica

\begin{tabular}{|c|c|c|c|c|c|}
\hline \multirow{3}{*}{ Você possui painéis solares instalados em sua residência? } & SIM & NÃO & TOTAL & & \\
\hline & 3 & 39 & 42 & & \\
\hline & $7 \%$ & $93 \%$ & $100 \%$ & & \\
\hline \multirow{3}{*}{$\begin{array}{l}\text { Qual o seu nível de conhecimento sobre energia a partir de } \\
\text { painéis fotovoltaicos? }\end{array}$} & Fraco & Moderado & Satisfatório & Muito bom & Excelente \\
\hline & 15 & 14 & 8 & 3 & 2 \\
\hline & $36 \%$ & $33 \%$ & $19 \%$ & $7 \%$ & $5 \%$ \\
\hline \multirow{2}{*}{$\begin{array}{l}\text { Qual o nível de importância dado por você e sua família } \\
\text { para o assunto? }\end{array}$} & 7 & 20 & 7 & 7 & 1 \\
\hline & $17 \%$ & $48 \%$ & $17 \%$ & $17 \%$ & $2 \%$ \\
\hline \multirow{2}{*}{$\begin{array}{l}\text { Em que grau de importância estão as medidas de redução de } \\
\text { consumo e uso consciente de energia elétrica você e sua } \\
\text { família adotam? }\end{array}$} & 6 & 12 & 12 & 8 & 4 \\
\hline & $14 \%$ & $29 \%$ & $29 \%$ & $19 \%$ & $10 \%$ \\
\hline \multirow{2}{*}{$\begin{array}{l}\text { Qual o grau de importância que você e sua família dão a } \\
\text { geração de energia para consumo oriunda de outras fontes / } \\
\text { matrizes energéticas? }\end{array}$} & 2 & 6 & 13 & 9 & 12 \\
\hline & $5 \%$ & $14 \%$ & $31 \%$ & $21 \%$ & $29 \%$ \\
\hline \multirow{2}{*}{$\begin{array}{l}\text { Você pagaria mais caro por uma energia de fonte mais } \\
\text { sustentável? }\end{array}$} & 8 & 10 & 14 & 6 & 4 \\
\hline & $19 \%$ & $24 \%$ & $33 \%$ & $14 \%$ & $10 \%$ \\
\hline \multirow{3}{*}{$\begin{array}{l}\text { Qual a média mensal de consumo em KWh em sua } \\
\text { residência? }\end{array}$} & 0 a $100 \mathrm{kWh}$ & 101 a $150 \mathrm{kWh}$ & 151 a $200 \mathrm{kWh}$ & 201 a $250 \mathrm{kWh}$ & $\begin{array}{c}\text { Acima de } 250 \\
\text { kWh }\end{array}$ \\
\hline & 6 & 9 & 13 & 6 & 8 \\
\hline & $14 \%$ & $21 \%$ & $31 \%$ & $14 \%$ & $19 \%$ \\
\hline \multirow{3}{*}{$\begin{array}{l}\text { Você compraria um sistema de geração de energia por } \\
\text { painéis fotovoltaicos (solares) mesmo que o valor da parcela } \\
\text { do investimento fosse maior que o valor de sua conta de luz } \\
\text { atualmente? }\end{array}$} & SIM & NÃO & & & \\
\hline & 25 & 17 & & & \\
\hline & $60 \%$ & $40 \%$ & & & \\
\hline \multirow{3}{*}{$\begin{array}{l}\text { Qual a maior dificuldade / impedimento para que você } \\
\text { adquira um sistema de geração de energia por painéis } \\
\text { solares em sua residência? }\end{array}$} & Custo do sistema & Falta de informaçōes & $\begin{array}{l}\text { Falta de políticas } \\
\text { incentivadoras }\end{array}$ & $\begin{array}{l}\text { Outro motivo } \\
\text { qualquer }\end{array}$ & \\
\hline & 20 & 6 & 13 & 3 & \\
\hline & $48 \%$ & $14 \%$ & $31 \%$ & $7 \%$ & \\
\hline
\end{tabular}

Fonte: Elaborado pelos autores (2018).

Por meio do perfil dos entrevistados, a pesquisa objetivou-se em uma análise sobre a instalação de um sistema solar fotovoltaico para a redução de valores pagos à concessionária de energia elétrica, efetuando-se o levantamento da política de atualização de preços historicamente praticadas, assim foram levantados na Tabela 2, os índices de reajuste de 1999 a 2017 da COPEL - Companhia Paranaense de Energia, encontrando a média de reajuste neste período de 9,05\% a.a., sendo este índice usado como base para a análise de viabilidade econômica do investimento. 
Tabela 2: Históricos de reajustes praticados pela COPEL

\begin{tabular}{|c|c|c|}
\hline Ano & Legislação & Reajuste \\
\hline 1999 & Resolução 194/99 Anexo I e II. & $12,99 \%$ \\
\hline 2000 & Resolução 194/99 Anexo III & $13,80 \%$ \\
\hline 2001 & Resolução 239/00 & $15,43 \%$ \\
\hline 2002 & Resolução 226/01 & $17,31 \%$ \\
\hline 2003 & Resolução 336/02 & $10,96 \%$ \\
\hline 2004 & Resolução ANEEL 284/03 & $15,00 \%$ \\
\hline 2005 & Resolução ANEEL 146/04 & $14,43 \%$ \\
\hline 2006 & Resolução 345/2006 & $3,30 \%$ \\
\hline 2007 & Resolução 479/2007 & $-1,27 \%$ \\
\hline 2008 & Resolução 663/2008. & $0,04 \%$ \\
\hline 2009 & Resolução 839/2009. & $5,00 \%$ \\
\hline 2010 & Resolução 1015/2010. & $2,46 \%$ \\
\hline 2011 & Resolução 1158/2011. & $2,99 \%$ \\
\hline 2012 & Resolução 1296/2012. & $-0,65 \%$ \\
\hline 2013 & Resolução 1565/2013; Resolução 1431/2013. & $-9,73 \%$ \\
\hline 2014 & Resolução 1763/2014. & $24,86 \%$ \\
\hline 2015 & Resolução 1897/2015; Resolução 1858/2015. & $52,11 \%$ \\
\hline 2016 & Resolução 1858/2015. & $-12,87 \%$ \\
\hline 2017 & Resolução 2255/2017. & $5,85 \%$ \\
\hline MÉDIA & & $9,05 \%$ \\
\hline
\end{tabular}

Fonte: Adaptado de COPEL - Companhia Paranaense de Energia (2018).

Em solicitações de orçamento a empresas de fornecimento e instalação de sistemas fotovoltaicos, para uma geração de $300 \mathrm{kWh}$ mês, foi selecionado o Fornecedor A devido aos valores apresentados mais satisfatórios. As características, especificações e investimentos necessários seguem elencados na Tabela 3. 
Tabela 3: Característica, especificação e investimento do sistema fotovoltaico

FICHA TÉCNICA

\begin{tabular}{l|c|c}
\hline Potencia a ser instalada & $\mathbf{k W p}$ & 2,16 \\
\hline Preço médio de instalação & $\mathbf{R \$}$ & $17.614,00$ \\
\hline Quantidade de placas fotovoltaicas & UN & 8,00 \\
\hline Produção anual de energia & $\mathbf{k W h} / \mathbf{A n o}$ & $3.600,00$ \\
\hline Área mínima do sistema & $\mathbf{M 2}$ & 16,00 \\
\hline Geração mensal de energia & $\mathbf{k W h} / \mathbf{M e ̂ s}$ & 300,00 \\
\hline Custo de instalação por kWh gerado ano & & 4,89 \\
\hline Modulo - geração de energia & anos & 25 \\
\hline Módulo - defeito de fabricação & anos & 10 \\
\hline Inversores - defeito de fabricação & anos & 5 \\
\hline Defeitos na instalação do sistema & Anos & 5 \\
\hline Unidade consumidora & Grupo & B \\
\hline
\end{tabular}

Fonte: Elaborado pelos autores (2018).

Outra variável importante para o estudo está contida na Resolução Normativa ANEEL no 414, de 09.09.2010, que estabelece condições gerais de fornecimento de energia elétrica, conforme seu Artigo 98 que regulamenta sobre o custo de disponibilidade:

\footnotetext{
"O custo de disponibilidade do sistema elétrico, aplicável ao faturamento mensal de consumidor responsável por unidade consumidora do grupo $\mathrm{B}$, é o valor em moeda corrente equivalente a: I. $30 \mathrm{kWh}$, se monofásico ou bifásico a 2 (dois) condutores; II. $50 \mathrm{kWh}$, se bifásico a 3 (três) condutores; ou III. $100 \mathrm{kWh}$, se trifásico. $\S 1^{\circ} \mathrm{O}$ custo de disponibilidade deve ser aplicado sempre que o consumo medido ou estimado for inferior aos referidos neste artigo, não sendo a diferença resultante objeto de futura compensação".
}

Para o estudo sobre a viabilidade econômica da instalação do sistema de energia fotovoltaica, foi utilizado o método com base no fluxo de caixa gerado no projeto, por meio da análise do período de payback simples e período de payback descontado. O payback é um método de análise capaz de evidenciar o tempo de recuperação do investimento o investimento inicial, o método simples não considera o valor do dinheiro no tempo, já essa consideração é feita pelo método 
descontado, pois utiliza uma taxa de desconto de atratividade como remuneração do capital investido.

Para formulação da TMA - Taxa Mínima de Atratividade, foi escolhido o rendimento acumulado da caderneta de poupança do ano de 2017 , conforme descrito na Tabela 4, correspondente a 6,99\% a.a. em dezembro de 2017.

Tabela 4: TMA - Taxa Mínima de Atratividade - Rendimento acumulado da Caderneta de Poupança do ano de 2017

\begin{tabular}{|c|c|c|c|c|c|c|c|c|c|c|c|c|}
\hline ANO/MÊS & JAN & FEV & MAR & ABR & MAI & JUN & JUL & AGO & SET & OUT & NOV & DEZ \\
\hline $\mathbf{2 0 1 7}$ & 0,6858 & 0,6709 & 0,5304 & 0,6527 & 0,5000 & 0,5768 & 0,5539 & 0,5626 & 0,5512 & 0,5000 & 0,5000 & 0,5000 \\
\hline ACUMULADO & $\mathbf{0 , 6 8 5 8}$ & $\mathbf{1 , 3 6 1 3}$ & $\mathbf{1 , 8 9 8 9}$ & $\mathbf{2 , 5 6 4 0}$ & $\mathbf{3 , 0 7 6 8}$ & $\mathbf{3 , 6 7 1 4}$ & $\mathbf{4 , 2 4 5 6}$ & $\mathbf{4 , 8 3 2 1}$ & $\mathbf{5 , 4 0 9 9}$ & $\mathbf{5 , 9 3 7 0}$ & $\mathbf{6 , 4 6 6 7}$ & $\mathbf{6 , 9 9 9 0}$ \\
\hline
\end{tabular}

Fonte: Adaptado de Base de dados do Portal Brasil ${ }^{\circledR}$ (2018).

Como o estudo leva em consideração as taxas histórias dos rendimentos da caderneta de poupança do ano de 2017, salientando que a política monetária brasileira é inconstante, assim dependendo do tipo de política praticada pelo governo, poderá impactar diretamente nas taxas de juros e processos inflacionários e, consequentemente, na economia, podendo viabilizar ou não diversos tipos de investimento.

$\mathrm{Na}$ Tabela 5, analisou-se o retorno do investimento contemplando as diversas variáveis envolvidas, em relação ao investimento com capital próprio, na questão temporal. Considerou-se o tempo de vida útil estimada de 25 anos do sistema, informada pelo fornecedor, observando que estará em operação de 2018 a 2042. O valor cobrado pela concessionária de energia foi estipulado com base no ano de 2018 no valor de $\mathrm{R} \$ 0,6675 \mathrm{kWh}$, acrescidos anualmente pelo índice médio de reajuste de 9,05\% a.a., Quanto ao consumo, estipulou-se $300 \mathrm{kWh}$ a.m., que equivalem a $3.600 \mathrm{kWh}$ a.a. para cálculo da tarifa anual correspondente, sabendo que serão cobrados pela concessionária, independendo do valor consumido, a quantia correspondente a $50 \mathrm{kWh}$ (grupo B bifásico) referente ao custo de disponibilidade.

Considerando o payback simples para a análise deste investimento, pode-se verificar na Tabela 5, que o investimento inicial de $\mathrm{R} \$ 17.614,00$ será recuperado em 6,75 anos, considerando os valores dos fluxos auferidos pelo não desembolso de pagamentos de energia elétrica à concessionária do ano de 2018 até parte do ano de 2024, já excluindo desse valor o custo de disponibilidade que continuará sendo desembolsado. Porém, o método simples não considera o valor do dinheiro no tempo, não sendo possível a comparação com um padrão de rentabilidade, como taxas oferecidas pelo mercado ou com o custo de capital.

Pelo cálculo do payback descontado, considerando a TMA - Taxa Mínima de Atratividade de 6,99\% a.a., serão necessários 8,73 anos, considerando o os valores dos fluxos auferidos pelo não desembolso de pagamentos de energia 
elétrica à concessionária do ano de 2018 até parte do ano de 2026, ou seja, o investimento terá retorno em $34,92 \%$ da vida útil estimada do bem.

Tabela 5: Retorno do Investimento, payback simples e descontado

\begin{tabular}{|c|c|c|c|c|c|c|c|c|c|c|c|}
\hline \multicolumn{2}{|c|}{ ANOS } & \multirow[t]{2}{*}{$\begin{array}{c}\text { Valor do } \\
\text { kWh com } \\
\text { impostos em } \\
\text { RS }\end{array}$} & \multirow[t]{2}{*}{$\begin{array}{l}\text { Com- } \\
\text { sumo } \\
\text { (kWh } \\
\text { a.a.) }\end{array}$} & \multirow[t]{2}{*}{ Tarifa Anual } & \multirow[t]{2}{*}{ 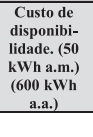 } & \multirow[t]{2}{*}{$\begin{array}{c}\text { Fluxo simples } \\
\text { em RS }\end{array}$} & \multirow{2}{*}{$\begin{array}{c}\begin{array}{c}\text { Payback } \\
\text { Simples em RS }\end{array} \\
(17.614,00) \\
\end{array}$} & \multirow[t]{2}{*}{$\begin{array}{c}\text { PB } \\
\text { anos }\end{array}$} & \multirow[t]{2}{*}{$\begin{array}{l}\text { Fluxo descontado } \\
6,99 \% \text { aa em RS }\end{array}$} & \multirow[t]{2}{*}{$\begin{array}{c}\begin{array}{c}\text { Payback } \\
\text { Descontado em } \\
\text { R\$ }\end{array} \\
(17.614,00)\end{array}$} & \multirow[t]{2}{*}{$\begin{array}{c}\text { PB } \\
\text { anos }\end{array}$} \\
\hline & & & & & & & & & & & \\
\hline 1 & 2018 & 0,6675 & 3600 & $2.402,82$ & 400,47 & $2.002,35$ & $(15.611,65)$ & & $1.871,53$ & $(15.742,47)$ & \\
\hline 2 & 2019 & 0,7279 & 3600 & $2.620,28$ & 436,71 & $2.183,56$ & $(13.428,09)$ & & $1.907,56$ & $(13.834,91)$ & \\
\hline 3 & 2020 & 0,7937 & 3600 & $2.857,41$ & 476,24 & $2.381,18$ & $(11.046,91)$ & & $1.944,30$ & $(11.890,61)$ & \\
\hline 4 & 2021 & 0,8656 & 3600 & $3.116,01$ & 519,33 & $2.596,67$ & $(8.450,24)$ & & $1.981,73$ & $(9.908,88)$ & \\
\hline 5 & 2022 & 0,9439 & 3600 & $3.398,00$ & 566,33 & $2.831,67$ & $(5.618,57)$ & & $2.019,89$ & $(7.889,00)$ & \\
\hline 6 & 2023 & 1,0293 & 3600 & $3.705,52$ & 617,59 & $3.087,94$ & $(2.530,63)$ & & $2.058,78$ & $(5.830,22)$ & \\
\hline 7 & 2024 & 1,1225 & 3600 & $4.040,87$ & 673,48 & \begin{tabular}{|l|l}
$3.367,39$ \\
\end{tabular} & 836,76 & 6,75 & $2.098,41$ & $(3.731,80)$ & \\
\hline 8 & 2025 & 1,2240 & 3600 & $4.406,57$ & 734,43 & $3.672,14$ & $4.508,90$ & & $2.138,82$ & $(1.592,99)$ & \\
\hline 9 & 2026 & 1,3348 & 3600 & $4.805,37$ & 800,89 & \begin{tabular}{|l|}
$4.004,47$ \\
\end{tabular} & $8.513,38$ & & $2.180,00$ & 587,01 & 8,73 \\
\hline 10 & 2027 & 1,4556 & 3600 & $5.240,25$ & 873,38 & $4.366,88$ & $12.880,25$ & & $2.221,98$ & $2.808,99$ & \\
\hline 11 & 2028 & 1,5874 & 3600 & $5.714,50$ & 952,42 & \begin{tabular}{l|l|}
$4.762,08$ \\
\end{tabular} & $17.642,33$ & & $2.264,76$ & $5.073,75$ & \\
\hline 12 & 2029 & 1,7310 & 3600 & $6.231,66$ & $1.038,61$ & $5.193,05$ & $22.835,38$ & & $2.308,36$ & $7.382,11$ & \\
\hline 13 & 2030 & 1,8877 & 3600 & $6.795,62$ & $1.132,60$ & \begin{tabular}{l|l}
$5.663,02$ \\
\end{tabular} & $28.498,40$ & & $2.352,81$ & $9.734,92$ & \\
\hline 14 & 2031 & 2,0585 & 3600 & $7.410,63$ & $1.235,10$ & \begin{tabular}{l|l|}
$6.175,52$ \\
\end{tabular} & $34.673,92$ & & $2.398,11$ & $12.133,03$ & \\
\hline 15 & 2032 & 2,2448 & 3600 & $8.081,29$ & $1.346,88$ & $6.734,41$ & $41.408,33$ & & $2.444,28$ & $14.577,31$ & \\
\hline 16 & 2033 & 2,4480 & 3600 & $8.812,65$ & $1.468,77$ & $7.343,87$ & $48.752,20$ & & $2.491,35$ & $17.068,66$ & \\
\hline 17 & 2034 & 2,6695 & 3600 & $9.610,19$ & $1.601,70$ & \begin{tabular}{l|l|}
$8.008,49$ \\
\end{tabular} & $56.760,69$ & & $2.539,31$ & $19.607,97$ & \\
\hline 18 & 2035 & 2,9111 & 3600 & $10.479,91$ & $1.746,65$ & $8.733,26$ & $65.493,95$ & & $2.588,21$ & $22.196,18$ & \\
\hline 19 & 2036 & 3,1745 & 3600 & $11.428,34$ & $1.904,72$ & $9.523,62$ & $75.017,57$ & & $2.638,04$ & $24.834,22$ & \\
\hline 20 & 2037 & 3,4618 & 3600 & $12.462,61$ & $2.077,10$ & $10.385,51$ & $85.403,08$ & & $2.688,83$ & $27.523,05$ & \\
\hline 21 & 2038 & 3,7751 & 3600 & $13.590,48$ & $2.265,08$ & $11.325,40$ & $96.728,48$ & & $2.740,61$ & $30.263,66$ & \\
\hline 22 & 2039 & 4,1168 & 3600 & $14.820,41$ & $2.470,07$ & $12.350,34$ & $109.078,82$ & & $2.793,37$ & $33.057,03$ & \\
\hline 23 & 2040 & 4,4894 & 3600 & $16.161,66$ & $2.693,61$ & $13.468,05$ & $122.546,87$ & & $2.847,16$ & $35.904,19$ & \\
\hline 24 & 2041 & 4,8956 & 3600 & $17.624,29$ & $2.937,38$ & $14.686,91$ & $137.233,78$ & & $2.901,98$ & $38.806,17$ & \\
\hline 25 & 2042 & 5,3387 & 3600 & $19.219,29$ & $3.203,21$ & $16.016,07$ & $153.249,85$ & & $2.957,85$ & $41.764,02$ & \\
\hline \multicolumn{9}{|c|}{ TIR - \% a.a. } & $8 \%$ a.a. & & \\
\hline \multicolumn{9}{|c|}{ VPL - R\$ } & $59.378,02$ & & \\
\hline
\end{tabular}

Fonte: Elaborado pelos autores (2018).

Nota-se ainda, na Tabela 5, que o VPL - Valor Presente Líquido ao final do vigésimo quinto ano será de $\mathrm{R} \$ 59.378,02$, ou seja, quanto ao valor dos fluxos auferidos pelo não desembolso de pagamentos de energia elétrica somados ao investimento inicial estariam valendo atualmente; apresentou uma TIR - Taxa Interna de Retorno de $8 \%$, indicando a rentabilidade do projeto comparada com a taxa mínima de atratividade; a qual foi considerada como uma remuneração que poderia ser obtida em outros investimentos, no caso a poupança, sendo a TIR superior à taxa de atratividade, estaria o investimento no projeto recomendado, concluindo que para uma TMA de $6,99 \%$ ao ano, o investimento em um projeto de energia solar fotovoltaica como alternativa para redução de custos é viável para o período analisado.

Na Tabela 6, estão apresentadas propostas de financiamento para a instalação do sistema em questão. Observa-se que as propostas estão relacionadas 
às duas Cooperativas de Crédito $(\mathrm{A})$ e $(\mathrm{B})$, um Banco privado $(\mathrm{A})$ e um Banco de encomia mista (B); os valores demonstram que a falta de análise da fonte de crédito e as taxas de custo de capital cobradas, podem inviabilizar um projeto de investimento, sendo que entre as instituições consultadas, a Cooperativa (A) com a melhor taxa entre as demais, apresentando um CET - Custo Efetivo Total de $8,99 \%$ a.a., com linha específica para energias sustentáveis, frisando que quando a escolha for a utilização de capital financiado, o tempo de payback sofrerá modificação, pela necessidade de cobertura dos juros de $\mathrm{R} \$ 4.139,84$ dentro dos cinco primeiros anos, prazo do financiamento.

Tabela 6: Propostas de Financiamento - Sistema de amortização Price

\begin{tabular}{|c|c|c|}
\hline $\begin{array}{c}\text { DADOS DO } \\
\text { FINANCIAMENTO }\end{array}$ & $\begin{array}{c}\text { COOPERATIVA } \\
\text { A } \\
\end{array}$ & $\begin{array}{c}\text { COOPERATIVA } \\
\text { B } \\
\end{array}$ \\
\hline Prazo & 60 meses & 60 meses \\
\hline $\begin{array}{l}\text { C.E.T. - Custo Efetivo Total - } \\
\text { a.a. }\end{array}$ & $8,99 \%$ a.a. & $19,8 \%$ a.a. \\
\hline Valor do principal & $\mathrm{R} \$ 17.614,00$ & $\mathrm{R} \$ 17.614,00$ \\
\hline Valor dos juros & R\$ 4.139,84 & R\$ 9.339,07 \\
\hline Valor Total & $\mathrm{R} \$ 21.753,84$ & $\mathrm{R} \$ 26.953,07$ \\
\hline Valor da parcela & $\mathrm{R} \$ 362,56$ & $\mathrm{R} \$ 449,22$ \\
\hline $\begin{array}{c}\text { DADOS DO } \\
\text { FINANCIAMENTO }\end{array}$ & BANCO A & BANCO B \\
\hline Prazo & 60 meses & 54 meses \\
\hline $\begin{array}{l}\text { C.E.T. - Custo Efetivo Total - } \\
\text { a.a. }\end{array}$ & $24,6 \%$ a.a. & $59,17 \%$ a.a. \\
\hline Valor do principal & $\mathrm{R} \$ 17.614,00$ & $\mathrm{R} \$ 17.614,00$ \\
\hline Valor dos juros & $\mathrm{R} \$ 12.806,00$ & R\$ 25.278,74 \\
\hline Valor Total & $\mathrm{R} \$ 30.420,00$ & $\mathrm{R} \$ 42.892,74$ \\
\hline Valor da parcela & $\mathrm{R} \$ 507,00$ & $\mathrm{R} \$ 794,31$ \\
\hline
\end{tabular}

Fonte: Elaborado pelos autores (2018).

Para Casarotto e Kopittke (2010) o método de cálculo do payback é mais adequado para avaliação de projetos de investimentos financiados totalmente com recursos próprios, quando estes forem financiados com recursos de terceiros, sugere-se após a identificação payback, se proceda a verificação se o VPL acumulado até o final do período é suficiente para quitar o saldo devedor remanescente, composto pelos juros e amortizações do financiamento. 


\section{CONSIDERAÇÕES FINAIS}

O estudo objetivou analisar a viabilidade econômico-financeira da instalação de um sistema de energia solar fotovoltaica, financiado por capitais próprios, com cálculos de análises financeiras como VPL, TIR, tempo de retorno de investimento, objetivando a possibilidade de redução de custos residenciais de energia elétrica.

Identificou-se que os entrevistados têm perfil de pequenos consumidores, concentrados em faixas de consumo superiores a $150 \mathrm{kWh}$ mensais, que estariam dispostos a investir em um sistema de energia fotovoltaica, mesmo com parcela de investimento acima do valor pago na atualidade em relação ao consumo de energia elétrica. Consideram que o custo do sistema e a falta de políticas de incentivo são as maiores dificuldades para o investimento.

Em relação aos dados encontrados por meio da análise do payback descontado, com TMA - Taxa Mínima de Atratividade de 6,99\% a.a., o investimento terá retorno em $34,92 \%$ da vida útil estimada do bem, sendo necessários 8,73 anos, considerando os valores dos fluxos gerados pela economia nos pagamentos de energia elétrica. Apresentou valor presente líquido ao final do vigésimo quinto ano será de R \$ 41.764,02, apresentando uma TIR - Taxa Interna de Retorno de $8 \%$, superior à taxa mínima de atratividade, recomendando-se o investimento no projeto.

Com os dados apresentados na pesquisa, considera-se a viabilidade econômico financeira da instalação de energia solar fotovoltaica, com benefícios se em uma taxa mínima de atratividade compatível com o rendimento acumulado da poupança no ano de 2017, além também de benefícios ambientais pelo uso de fonte de energia renovável.

Sugere-se que sejam feitos outros estudos relacionados aos investimentos com origem de capitais de terceiros e possíveis impactos causados por política monetária em relação as taxas de juros e processos inflacionários, servindo para análise de viabilidade para novos investimentos em energia fotovoltaica.

\section{REFERÊNCIAS}

ABSOLAR - Associação Brasileira de Energia Solar Fotovoltaica. 2018. $<$ http://www.absolar.org.br/noticia/noticias-externas/solar-fotovoltaica-a-fonterenovavel-do-seculo-xxi.html>. Acesso em 20 de maio de 2018.

ALMEIDA, J. Da ideologia do progresso à ideia de desenvolvimento (rural) sustentável. In: Almeida, J.; Navarro, Z. (Org.). Reconstruindo a agricultura: ideias e ideais na perspectiva de um desenvolvimento rural sustentável. Porto 
Alegre: UFRGS, p. 33-55, 1997.

ASSAF NETO, A.; LIMA, F.G. Curso de administração financeira. São Paulo: Atlas, 2009.

BARBIERI, J. C. Gestão ambiental empresarial. São Paulo: Saraiva 2. ed. 2007.

CAMARGOS, M. Matemática financeira: aplicada a produtos financeiros e à análise de investimentos. São Paulo: Saraiva, 2013.

CASAROTTO, N. F.; KOPITTKE, B. H. Análise de Investimentos: matemática financeira, engenharia econômica, tomada de decisão, estratégia empresarial. 11. ed. São Paulo: Atlas, 2010. 411p.

COPEL - Companhia Paranaense de Energia http://www.copel.com/hpcopel/ root $/$ nivel2.jsp?endereco=\%2Fhpcopel $\% 2$ Froot $\% 2$ Fpagcopel $2 . n s f \% 2 F d o c s \% 2$ F04AFB43850CA33C503257488005939B7. Acesso em 20 maio 2018.

DAL SOGLIO, F.; KUBO, R. R. Agricultura e sustentabilidade. PLAGEDER, 2009.

DUPONT, F. H GRASSI, F.; ROMITTI, L. Energias Renováveis: buscando por uma matriz energética sustentável. Revista Eletrônica em Gestão, Educação e Tecnologia Ambiental. 2015. v. 19, n. $170-80$ p.

GARRISON, R. H., NOREEN, E. W., BREWER, P. C. Contabilidade Gerencial. 14. ed. Porto Alegre: AMGH, 2012.

GIL, A. C. Como elaborar projetos de pesquisa. 4. ed. São Paulo: Atlas, 2008.

GOLDEMBERG. J. Energia e Sustentabilidade. Revista de Cultura e Extensão USP. São Paulo, n. 14, p.33-43, nov 2015.

IMHOFF, J. Desenvolvimento de Conversores Estáticos para Sistemas Fotovoltaicos Autônomos. Dissertação de Mestrado apresentada à Escola de Engenharia Elétrica da Universidade Federal de Santa Maria, Santa Maria, 2007.

MACHADO, C. T.; MIRANDA, F. S. Energia Solar Fotovoltaica: Uma Breve Revisão. Rev. Virtual Quim., 2015, vol. 7 (No.1), 126-143p. Data de publicação na Web: 14 de outubro de 2014. 
NASCIMENTO, R. L. Energia solar no Brasil: situação e perspectivas. Estudo técnico. Consultoria legislativa. Março de 2017. 46 p.

PALLIS, J. CRUZ, C. H. B. Energia sustentável para o desenvolvimento. Um futuro com energia sustentável: iluminando o caminho. 2010. p.5. URL: $<$ http:// www.fapesp.br/publicacoes/energia.pdf>.

Portal Brasil ${ }^{\circledR}$ Base de dados. Caderneta de Poupança - índices mensais (1967 - 2018). Disponível em: <http://www.portalbrasil.net/poupanca_mensal.htm>. Acesso em 10 de maio de 2018.

REN 21 (Renewable Energy Policy Network for the 21st Century). Renewables 2013: Global Status Report. 2013. Disponível em $<$ www.ren21.net $>$. Acesso em 04 de maio de 2018.

. (Renewable Energy Policy Network for the 21st Century). Renewables 2015: Global Status Report. 2015. Disponível em <www.ren21.net $>$. Acesso em 04 maio. 2018.

SACHS, I. Caminhos para o desenvolvimento sustentável: ideias sustentáveis. Organização: Paula Yone Stroh. Rio de Janeiro: Garamond, 2009.

SHAYANI, R. A.; OLIVEIRA, M. A. G.; CAMARGO, I. M. T. Comparação do custo entre Energia Solar Fotovoltaica e Fontes Convencionais. Políticas públicas para a Energia: Desafios para o próximo quadriênio. 31 de maio a 02 de junho de 2006. Brasília - DF.

UTFPR - Universidade Tecnológica Federal do Paraná. Atlas de Energia Solar do Paraná. <http://www.atlassolarparana.com/map >. Acesso em 20 de maio de 2018. 